\title{
Editorial: Biology and Management of Weeds and Invasive Plant Species Under Changing Climatic and Management Regimes
}

\author{
Ali Bajwa ${ }^{1 * t}$, Maor Matzrafi ${ }^{2+}$ and Mithila Jugulam ${ }^{3 \dagger}$ \\ ${ }^{1}$ Weed Research Unit, New South Wales Department of Primary Industries, Wagga Wagga, NSW, Australia, ${ }^{2}$ Department of \\ Plant Pathology and Weed Research, Newe Ya'ar Research Center, Agricultural Research Organization, Ramat-Yishay, Israel, \\ ${ }^{3}$ Department of Agronomy, Kansas State University, Manhattan, KS, United States
}

Keywords: climate change, weed biology, weed ecology, invasive plants, weed management

\section{Editorial on the Research Topic}

Biology and Management of Weeds and Invasive Plant Species Under Changing Climatic and Management Regimes

The global climate is changing rapidly. Rising levels of atmospheric carbon dioxide, erratic precipitation, and warmer temperatures have significant effects on biology and distribution of plant species. These climatic changes are also known to alter biology, distribution, interference potential, and management of weeds and invasive plant species (Varanasi et al., 2016; Ziska, 2016; Matzrafi, 2018; Chauhan, 2020; Rice et al., 2021). The objective of this Research Topic is to advance our understanding of the impact of rapidly changing climatic and management regimes on biology, ecology, and management of weeds and invasive species. We accepted five research articles and four review articles contributed from six countries of Asia-Pacific, Europe, and North America. The key focus of these contributions is on how climatic changes impact emergence, establishment, adaptive evolution, and management of some of the most problematic weeds and invasive species.

The ability to successfully germinate and establish early under harsh conditions was recognized as a key adaptive strategy for many weeds and invasive species under changing climate in this Topic. For instance, Yair et al. investigated the germination ecology and growth behavior of three Ambrosia weed species under temperature stress in Israel. They reported that Ambrosia confertiflora showed a dramatic shift from a naturalized to invasive species status and it outperformed other species under high temperature stress. Further, rapid growth and fast sprouting were suggested to be the contributing factors for superior competitive ability and stress tolerance in this species. In another study, Matzrafi et al. documented the current invasion status of Parthenium hysterophorus in Israel and they also studied the life cycle and biology of a local population of this species. New invasions were recorded in several locations across the northern part and Mediterranean coastal plain of Israel. The optimal temperature range $\left(15-25^{\circ} \mathrm{C}\right)$ and soil depth $(0-3 \mathrm{~cm})$ for germination were also reported in this study. Shading was found to be a limiting factor for biomass accumulation, height, and flowering in P. hysterophorus. From Australia, Wu et al. studied the seed biology of Panicum capillare and found that germination was stimulated by light and was better at both constant and alternating temperatures over $20^{\circ} \mathrm{C}$. They found that seeds of $P$. capillare were fairly persistent in the soil seedbank (up to 4 years) and can germinate under high moisture stress/low water potential $(-0.48 \mathrm{MPa})$. These studies suggest that weeds can quickly adapt to changing environmental conditions to ensure their successful emergence and establishment which contributes toward their invasion success. 
The role of different ecological, physiological, and genetic traits in adaptive evolution of weeds under changing climate is also well-explored in this Research Topic. In a review article, Clements and Jones argued that accelerated climate change is causing rapid evolution in many weeds through multiple evolutionary mechanisms such as genetic modifications, changes in plant morphology, phenology and physiology, and niche shifts. The authors suggested that this rapid evolution could enable range expansion of many weeds and invasive plants while making their management a challenge. In another review, Rutland et al. suggested that future climatic changes may favor polyploid species; however, limited data are available for weedy species to make meaningful speculations in this regard. Thus, authors proposed that understanding of genomics and molecular biology of polyploid species will help elucidate weed adaptation to climate change. In recent years, several agronomically important weed species have been sequenced and the data are made publically available. Such data will help decipher the genes that help weedy species to cope with harsh climatic conditions. Stallworth et al. screened a mini germplasm collection of weedy rice/red rice (Oryza sativa spp.), and found that certain accessions may possess traits to withstand heat stress as well as perform well under submerged conditions, enabling this problematic weed to thrive under severe conditions. They proposed that these accessions could be used in breeding programs to develop cultivated rice varieties suitable for future climate. Adhikari et al. assessed the variability and heritability of different phenotypic functional traits within distinct populations of Anthemis cotula (from different land-use and geographic conditions) in the Pacific Northwest region of the USA. The authors noted significant variations within populations with high heretability, suggesting that weed populations can adapt quickly under different climatic and management regimes, making the task of management more difficult.

There is reasonable literature available on generalistic impacts of climate change on weed dynamics in agroecosystems, but the region-specific information for some of the most vulnerable areas has been scarce. Marambe and Wijesundara reviewed the current and potential impacts of climate change on spread,

\section{REFERENCES}

Chauhan, B.S. (2020). Grand challenges in weed management. Front. Agron. 1:3. doi: 10.3389/fagro.2019.00003

Matzrafi, M. (2018). Climate change exacerbates pest damage through reduced pesticide efficacy. Pest Manag. Sci. 75, 9-13. doi: 10.1002/ps.5121

Rice, C., Wolf, J., Fleisher, D. H., Acosta, S. M., Adkins, S. W., Bajwa, A. A., et al. (2021). Recent $\mathrm{CO}_{2}$ levels promote increased production of the toxin parthenin in an invasive Parthenium hysterophorus biotype. Nat. Plants 7, 725-729. doi: 10.1038/s41477-021-00 938-6

Varanasi, A., Prasad, P. V. V., and Jugulam, M. (2016). Impact of climate change factors on weeds and herbicide efficacy. Adv. Agron. 135, 107-146. doi: 10.1016/bs.agron.2015.09.002

Ziska, L. H. (2016). The role of climate change and increasing atmospheric carbon dioxide on weed management: herbicide efficacy. interference and management of numerous weeds and invasive plants in an agricultural context in Sri Lanka. They stressed that agroecosystem of the Island nation are under extreme pressure of biological invasions in the wake of rapid climatic changes and therefore, comprehensive risk assessment systems and coordinated management efforts are urgently needed. Finally, a collaborative article by weed scientists from Switzerland and Iran addressed the contentious, yet important topic of the lack of collaboration between the disciplines of weed science and invasion ecology in addressing the climate change impacts (Sun et al.). They argued that a more inter-disciplinary approach with better knowledge sharing could help mitigate the climate-mediated biological invasions and failing weed management crises.

In conclusion, weed scientists across the world, recognize the impacts of climate change on weed management and invasion. There is a need to further understand the fundamental biological mechanisms which enable weeds' success as well as future proofing for integrated weed management programs. In recent years, considerable emphasis has been given to understand basic aspects of biology and ecology of weedy and invasive species. However, the need for further work in a climate change context is imminent.

\section{AUTHOR CONTRIBUTIONS}

$\mathrm{AB}, \mathrm{MM}$, and $\mathrm{MJ}$ contributed equally in organizing this Research Topic and writing this editorial based on the contributed articles. All authors contributed to the article and approved the submitted version.

\section{ACKNOWLEDGMENTS}

We thank the Speciality Chief Editor for the opportunity to edit this important Research Topic and the Journal Specialist for her consistent technical support. We are also thankful to all the authors for their excellent contributions and the reviewers for critically evaluating the manuscripts. The co-editors also greatly acknowledge the on-going financial and strategic support from their respective institutes.
Agric. Ecosyst. Environ. 231, 304-309. doi: 10.1016/j.agee.2016.0
7.014

Conflict of Interest: The authors declare that the research was conducted in the absence of any commercial or financial relationships that could be construed as a potential conflict of interest.

The handling editor declared a past collaboration with one of the authors AB.

Copyright (c) 2021 Bajwa, Matzrafi and Jugulam. This is an open-access article distributed under the terms of the Creative Commons Attribution License (CC BY). The use, distribution or reproduction in other forums is permitted, provided the original author(s) and the copyright owner(s) are credited and that the original publication in this journal is cited, in accordance with accepted academic practice. No use, distribution or reproduction is permitted which does not comply with these terms. 